\title{
Continuous 24-hour ocular dimensional profile recording in medically treated normal-tension glaucoma
}

This article was published in the following Dove Press journal:

Clinical Ophthalmology

29 January 2015

Number of times this article has been viewed

\author{
Jacky WY Lee ${ }^{1,2}$ \\ Lin Fu' \\ Jennifer WH Shum' \\ Jonathan $\mathrm{CH} \mathrm{Chan}^{3}$ \\ Jimmy SM Lai'
}

'Department of Ophthalmology, The University of Hong Kong, Hong Kong; ${ }^{2}$ Department of Ophthalmology,

Caritas Medical Centre, Hong Kong;

${ }^{3}$ Department of Ophthalmology,

Queen Mary Hospital, Hong Kong
Correspondence: Jacky WY Lee Department of Ophthalmology, Caritas Medical Centre, II I Wing Hong St, Kowloon, Hong Kong

Tel +8523408 79lI

Fax +85223070582

Email jackywylee@gmail.com
Purpose: To analyze the 24-hour ocular dimensional profile in normal-tension glaucoma (NTG) patients on medical treatment.

Methods: Consecutive, medically treated NTG subjects were recruited from a university eye center. Subjects were on a mean of $1.7 \pm 0.7$ types of antiglaucoma medications and $56.6 \%$ were on a prostaglandin analog. A contact lens-based sensor device was worn in one eye of NTG patients to record the intraocular pressure (IOP)-related profile for 24 hours, recording the following: variability from mean over 24 hours, nocturnally and diurnally, as well as the number of peaks and troughs diurnally and nocturnally.

Results: In 18 NTG subjects, the nocturnal variability around the mean contact lens-based sensor device signal was $48.9 \%$ less than the diurnal variability around the mean. The number of peaks was $54.7 \%$ less during the nocturnal period than during the diurnal period. The rate of increase in the ocular dimensional profile when going to sleep was significantly greater than the rate of decrease upon waking $(P<0.001)$.

Conclusion: In medically treated NTG subjects, there was more variability in the IOP-related pattern during the daytime and there were fewer peaks during sleep.

Keywords: intraocular pressure, 24-hour, normal tension glaucoma

\section{Background}

Intraocular pressure (IOP) is one the most important modifiable risk factors for glaucoma progression. ${ }^{1-3}$ IOP measurements in the ophthalmology clinic are often limited to office hours, which do not fully represent the nychthemeral IOP peaks and fluctuations. ${ }^{4,5}$ Previously, 24-hour IOP monitoring studies have reported fluctuation as high as $8.2 \pm 1.4 \mathrm{mmHg}$, but many of these studies measured IOP in the sitting position, overnight in a hospital environment, and over a few sampling periods, which does not truly reflect the physiological and normal setting of one's daily living, especially when the subjects are awakened at night for IOP measurements. ${ }^{6-10}$

Various studies have reported the significance of IOP fluctuation on glaucoma progression. ${ }^{11,12}$ While there are studies that report otherwise, ${ }^{13,14}$ much of the existing literature has only documented inter-visit or daytime IOP variability over a limited number of hours. This is at least partly due to limitations of how frequently repeated tonometric IOP measurements can be taken.

A contact lens-based sensor (CLS) is nowadays available for the recording of ocular dimensional profiles for up to 24 hours. ${ }^{15}$ This device has been shown to be safe and tolerable in healthy subjects and glaucoma patients as well as to provide reproducible recording of 24-hour profiles. ${ }^{16-18}$ 
The aim of this study was to analyze the 24-hour ocular dimensional profile in normal-tension glaucoma (NTG) patients on medical treatment.

\section{Methods}

This study adhered to the tenets of the Declaration of Helsinki. Informed patient consent and approval by the Institutional Review Board of the Hospital Authority of Hong Kong were obtained prior to study commencement.

This was a prospective cohort study from July 2012 to June 2013, conducted at a university hospital in Hong Kong. The study recruited consenting adults (age $>18$ years old) with unilateral or bilateral NTG who were currently on topical antiglaucoma medications. NTG was defined as open angle on gonioscopy; progressive thinning of the retinal nerve fiber layer (RNFL) on optical coherence tomography, with corresponding glaucomatous visual field changes on the Humphrey Visual Field Analyzer; and an IOP $\leq 21 \mathrm{mmHg}$ on all clinical visits based on previous medical records. Cases with previous glaucoma surgery or laser treatment, active or previous corneal disease, and subjects with only one functional eye were excluded.

The SENSIMED Triggerfish ${ }^{\circledR}$ (Sensimed AG, Lausanne, Switzerland) is a soft silicone CLS that enables recording of the ocular dimensional profile over a 24-hour period with minimal disturbance to one's daily routines and sleep cycles. Such 24-hour profiles are related to the 24-hour IOP profiles. ${ }^{18}$ Dimensional changes are recorded in the corneoscleral area for 30 seconds every 5 minutes over 24 hours and each recording "burst" represents 300 data points, the medians of which are plotted as a single graph which makes up the 24-hour ocular dimensional profile measured in sensory output units of millivolt equivalents (mVeq). The device was CE-marked and thus approved for clinical use in 2009. In healthy volunteers and glaucoma patients, the CLS was found to be tolerable in normal activities of daily living and during sleep. A contact lens with base curve $8.7 \mathrm{~mm}$ was also found to be well adapted in most eyes, although the device also exists in steeper $(8.4 \mathrm{~mm})$ and flatter $(9.0 \mathrm{~mm})$ base curves. ${ }^{16-18}$

The CLS was placed on the subject's eye by an ophthalmologist in the outpatient clinic after a slit-lamp examination of the anterior segment and Goldmann applanation tonometry (GAT) by a single investigator. For those with unilateral disease, the CLS was placed on the eye with NTG. For those with bilateral disease, a random eye assignment by card shuffling was used to determine the eye for the CLS placement. The subject then returned home with lubricating eyedrops and carried on his or her daily activities (both indoor and outdoor), apart from showering or swimming (as the device cannot be in contact with water). Subjects continued their same regimen of antiglaucoma eyedrops and slept in their habitual position at night. Each subject carried a logbook to record sleeping times during the 24-hour period. After 24 hours, the subject returned to the clinic to have the CLS removed followed by a slit-lamp examination and GAT. The data recorded by the SENSIMED Triggerfish ${ }^{\circledR}$ device were uploaded into a computer database. CLS profile parameters were extracted following smoothing of the profile using locally weighted polynomial regression.

\section{Definitions}

- CLS variability from mean: this variable reflects variability around the mean value of all raw (not smoothed) CLS measurements in the respective period (24-hour, diurnal, or nocturnal).

- Diurnal/nocturnal variability: same as above but only during the awake and asleep periods, respectively, where the sleep cycle is determined from recorded sleep times in each individual's logbook and verified by the eye-blinking frequency (present during waking) and the presence of rhythmic ocular pulsation waves (present during sleep).

- Sleep-to-wake and wake-to-sleep slopes: calculated with a generalized linear model on raw measurements in units of $\mathrm{mVeq} /$ hour from 1 hour before sleep or wake time to 1 hour after sleep or wake time, respectively.

- Number of peaks: a peak is defined as a local maximum point in the smoothed curve. The calculation of the number of peaks occurs as follows: each trough is noted as the start of a peak.

\section{Statistical analysis}

The pre- and post-CLS GAT IOPs were compared using the Wilcoxon signed-rank test. The following parameters, extracted from CLS profiles, were compared using the Mann-Whitney $U$-test:

1. nocturnal versus diurnal mean variability from mean;

2. wake-to-sleep versus sleep-to-wake slopes;

3. number of nocturnal versus diurnal peaks; and

4. 24-hour, diurnal, and nocturnal variability among prostaglandin users and nonusers.

Fisher's exact test was used to compare the differences in the number of nocturnal peaks between those using a prostaglandin antiglaucoma medication versus those using other, non-prostaglandin antiglaucoma medications. Statistical significance was taken as $P<0.05$. 


\section{Results}

In the 18 subjects enrolled in the study, there were seven males and eleven females. The mean age was $65.1 \pm 13.7$ years. GAT IOPs before and after the CLS wear were $15.3 \pm 2.2$ and $13.8 \pm 1.7 \mathrm{mmHg}$, respectively, while on the same antiglaucoma medications $(P=0.05)$. The mean RNFL thickness was $72.9 \pm 9.8 \mu \mathrm{m}$ and the mean deviation and pattern standard deviation on Humphrey visual field analysis were $-6.3 \pm 4.5$ decibels $(\mathrm{dB})$ and $6.1 \pm 4.1 \mathrm{~dB}$, respectively.

The mean number of antiglaucoma eyedrops was $1.7 \pm 0.7$. In the 18 subjects, $38.9 \%$ (7/18) used a single prostaglandin eyedrop administered in the evening, 44.4\% (8/18) used a twice-daily non-prostaglandin eyedrop, and $17.6 \%(3 / 17)$ used both a nocturnal prostaglandin eyedrop plus a twicedaily antiglaucoma eyedrop.

The mean 24-hour variability from the mean CLS signal was $75.9 \pm 21.5$ (range: $35.7-120.9 ; 95 \%$ confidence interval [CI]: 62.8-86.7) mVeq. The mean nocturnal variability from the mean was $52.1 \pm 20.3$ (range: $23.9-105.1 ; 95 \% \mathrm{CI}$ : 41.6-62.5) $\mathrm{mVeq}$, which was $48.9 \%$ less than the mean diurnal variability from the mean (77.6 \pm 20.6$)$ (range: 43.9-118.4; 95\% CI: 66.9-88.2) mVeq ( $P=0.002)$. There were no statistically significant differences in the mean diurnal, nocturnal, or 24-hour variability between those with and without prostaglandin analog treatment (all $P>0.1$ ) (Table 1).

The mean number of peaks during sleep and daytime was $6.4 \pm 2.3$ and $9.3 \pm 2.4$, respectively. The number of peaks was $54.7 \%$ less during the nocturnal period than the diurnal period ( $P=0.001)$. There was no significant difference between the frequencies of nocturnal peaks among those using a prostaglandin antiglaucoma medication versus those using other, non-prostaglandin antiglaucoma medications (Table 2).

The mean sleep time of subjects was from $8.53 \mathrm{pm} \pm 12.6$ minutes to 7.06 am \pm 3.6 minutes. The study population had a mean positive linear slope on their CLS profile from wake-to-sleep with a mean of $53.2 \pm 42.9$ $\mathrm{mVeq} /$ hour, signifying an increase in the ocular dimensional profile when going to sleep. Similarly, the population had a mean negative linear slope from sleep-to-wake with a mean of $-42.5 \pm 47.6 \mathrm{mVeq} / \mathrm{hour}$, signifying a decrease in the ocular dimensional profile upon waking. On comparing the two slopes, the rate of increase when going to sleep was significantly greater than the rate of decrease upon waking $(P<0.001)$ (Table 3$)$.

\section{Discussion}

The ocular dimensional profiles of all 18 NTG subjects were unique, with individual peaks occurring at different time intervals throughout the day and night; no two tracings were identical. The mean ocular dimensional profile of the study population increased during sleep (positive wake-to-sleep slope) and decreased upon waking (negative sleep-to-wake slope), with the mean rate of increase during sleep being significantly greater than the rate of decrease upon waking $(P<0.001)$. We are inclined to agree with previous postulations, wherein the increase in nocturnal IOP was thought to be related to the gravitational pull of fluids to the eye and an increase in episcleral venous pressure during the supine sleep posture. ${ }^{19}$ Through the use of the 24-hour CLS, we affirm that the phenomenon of increased IOP with supine posturing was consistent among NTG subjects under medical treatment. Other authors have also observed the persistence of posture-induced IOP changes despite treatment of NTG patients with IOP-lowering medication. ${ }^{20}$ Similarly, a previous Japanese study reported, in a population of NTG subjects, that the IOP spikes recorded from the habitual positions (sitting up during the day and supine at night) were positively correlated to the spikes induced from a postural-change test and after a water-drinking test. ${ }^{21}$ In contrast, Renard et al reported that, in 27 subjects with suspected NTG, 24-hour IOP monitoring revealed that $54.5 \%$ exhibited a diurnal acrophase and $36.4 \%$ exhibited a nocturnal acrophase, while $9.1 \%$ had no nychthemeral rhythm in the absence of medical treatment. ${ }^{22}$ The existence of concomitant obstructive sleep apnea syndrome in $80 \%$ of assessed patients could have influenced the observed IOP rhythm in their cohort. ${ }^{22}$

Before the availability of continuous 24-hour ocular dimensional profile recording, it has been reported that, in many glaucoma patients, the IOP peaks occurred outside of office hours ${ }^{23,24}$ and that two-thirds of IOP peaks in untreated glaucoma patients occurred during the nocturnal period. ${ }^{25}$

Table I Mean 24-hour, diurnal, and nocturnal variability among subjects with and without prostaglandin analog treatment

\begin{tabular}{llll}
\hline & $\begin{array}{l}\text { Subjects on prostaglandin } \\
\text { analogs }(\mathbf{n = 9})\end{array}$ & $\begin{array}{l}\text { Subjects not on prostaglandin } \\
\text { analogs }(\mathbf{n}=\mathbf{8})\end{array}$ & $\begin{array}{c}\text { P-value } \\
\text { Mean 24-hour variability }(\mathrm{mVeq})\end{array}$ \\
Mean diurnal variability (mVeq) & $84.8 \pm 20.3$ & $71.1 \pm 17.2$ & 0.1 \\
Mean nocturnal variability $(\mathrm{mVeq})$ & $85.4 \pm 22.3$ & $68.7 \pm 15.4$ & 0.1 \\
\hline
\end{tabular}

Note: Sleep data are missing for subject 18, thus, this subject's data was not included in the variability calculations. 
Table 2 Frequency distribution of number of peaks during the nocturnal period in subjects with and without prostaglandin treatment

\begin{tabular}{|c|c|c|c|c|c|c|c|}
\hline \multirow{3}{*}{$\begin{array}{l}\text { Number of peaks during } \\
\text { the nocturnal period }\end{array}$} & \multicolumn{4}{|c|}{ Patients treated with prostaglandins } & \multirow{2}{*}{\multicolumn{2}{|c|}{ All }} & \multirow{3}{*}{$\begin{array}{l}P \text {-value for comparison } \\
\text { between prostaglandin } \\
\text { groups }\end{array}$} \\
\hline & \multicolumn{2}{|c|}{ Yes } & \multicolumn{2}{|c|}{ No } & & & \\
\hline & $\mathbf{N}$ & $\%$ & $\mathbf{N}$ & $\%$ & $\mathbf{N}$ & $\%$ & \\
\hline 5 & 0 & 0 & 1 & 11.1 & 1 & 5.9 & \\
\hline 6 & I & 12.5 & I & II.I & 2 & 11.8 & \\
\hline 7 & 0 & 0 & I & II.I & I & 5.9 & \\
\hline 8 & 0 & 0 & I & $\mathrm{II} . \mathrm{I}$ & 1 & 5.9 & \\
\hline 9 & 3 & 37.5 & I & II.I & 4 & 23.5 & \\
\hline 10 & I & 12.5 & 3 & 33.3 & 4 & 23.5 & \\
\hline 11 & I & 12.5 & 0 & 0 & I & 5.9 & \\
\hline 13 & 2 & 25.0 & I & 11.1 & 3 & 17.6 & \\
\hline All & 8 & 100.0 & 9 & 100.0 & 17 & 100.0 & 0.7 \\
\hline
\end{tabular}

Note: Sleep data are missing for subject 18, thus the number of peaks during the nocturnal period could not be calculated for this subject.

In our NTG population, we noted that there were $55 \%$ less peaks occurring nocturnally than diurnally $(P=0.001)$. The reduction in the number of peaks at night in our NTG population could be related to the use of prostaglandin antiglaucoma eyedrops, since $57 \%$ of our subjects were at least on prostaglandin antiglaucoma eyedrops nocturnally. However, it may also be simply due to the absence of physical activity, eye blinking, and saccadic movements at night, as these parameters are known to cause IOP spikes and fluctuations. ${ }^{26}$ Other authors have suggested that the nocturnal IOP and IOP spikes may be related to visual field progression in NTG subjects. ${ }^{21}$

Study on the effect of medical treatment on IOP fluctuations has shown that prostaglandin antiglaucoma eyedrops offer the best sustained 24-hour IOP reduction, while brimonidine offers the least. ${ }^{27}$ In our study, the mean nocturnal variability was significantly lower than the mean diurnal variability by $49 \%(P=0.002)$. Our findings are in agreement with a previous study by Pajic et $\mathrm{a}^{28}$ reporting higher coefficients of variation in CLS data during the daytime than at nighttime in NTG patients. Pajic et al reported reduced variability in nocturnal CLS data independent of whether or not patients were on antiglaucoma medication. ${ }^{28}$ We have not recorded CLS profiles in our patients without medical treatment and therefore do not know whether the same is valid for this patient cohort; however, it seems plausible that the lower level of activity during sleep provides a natural reduction in variability, which IOP-lowering medical treatment may further influence. Holló et al recorded CLS profiles in primary open-angle glaucoma and ocular hypertension patients and found no difference in 24-hour, diurnal, or nocturnal standard deviation of CLS values in the presence of prostaglandin analog treatment as compared to without treatment. ${ }^{29}$ The variability of diurnal versus nocturnal CLS values was not evaluated. Thus, in this patient cohort, it seems that, while the overall ocular dimensional profile was higher at night, the number of peaks and variability from the mean were significantly reduced at night for NTG subjects on medical treatment. The use of prostaglandins did not significantly affect the CLS variability $(P>0.1)$.

It was interesting to note that the GAT IOP after CLS wear $(13.8 \pm 1.7 \mathrm{mmHg})$ was lower $(P=0.05)$ than the IOP before the CLS wear $(15.3 \pm 2.2 \mathrm{mmHg})$, although the readings were measured exactly 24 hours apart. This seemingly lower IOP after the CLS use was short of statistical significance and can be explained by day-to-day variations in IOP.

There were limitations in this study. There was no sample size calculation, and the relatively small sample size of the study did not allow for evaluation of differences in IOPrelated pattern nor stratification by the type of treatment. Furthermore, only one 24-hour measurement with the CLS was performed, therefore we could not ascertain the reproducibility of the 24-hour IOP profile. At present, the ocular dimensional profile is something that cannot be translated

Table 3 SENSIMED Triggerfish ${ }^{\circledR}$ contact lens-based sensor 24-hour parameters in diurnal versus nocturnal periods

\begin{tabular}{llll}
\hline & Diurnal & Nocturnal & $P$-value \\
\hline Variability (mVeq) & $77.6 \pm 20.6$ & $52.1 \pm 20.3$ & $0.002^{*}$ \\
Peaks (number) & $9.3 \pm 2.4$ & $6.4 \pm 2.3$ & $0.00 I^{*}$ \\
Slopes (mVeq/hour) & $53.2 \pm 42.9$ (wake-to-sleep) & $-42.5 \pm 47.6$ (wake-to-sleep) & $<0.00 I^{*}$ \\
\hline
\end{tabular}

Note: *Statistically significant. 
into IOP and therefore has no validation for use in clinical practice. Additional clinical research needs to be done before we can state (based on evidence) that the CLS can be useful in optimizing the timing of medical therapy for individual patients. Nevertheless, this is one of the few publications in the literature analyzing the 24-hour ocular dimensional profile on a continuous basis in NTG subjects receiving medical treatment.

\section{Conclusion}

Continuous 24-hour ocular dimensional profiles recorded in NTG patients on medical treatment revealed that the profile increased during sleep and decreased upon waking. There was a $50 \%$ reduction in both the variability from the mean and number of peaks during sleep as compared to daytime.

\section{Acknowledgments}

The authors would like to thank Ms Lee Man Yee and her dedicated team of nursing and clerical staff for their support in research.

\section{Author contributions}

All authors 1) have made substantial contributions to conception and design, acquisition of data, or analysis and interpretation of data; 2) have been involved in drafting the manuscript or revising it critically for important intellectual content; 3) have given final approval of the version to be published; and 4) agree to be accountable for all aspects of the work in ensuring that questions related to the accuracy or integrity of any part of the work are appropriately investigated and resolved.

\section{Disclosure}

This study was supported by the provision of the SENSIMED Triggerfish ${ }^{\circledR}$ CLS, other device items, and publication-related expenses by Sensimed. The authors report no other conflicts of interest in this work. They have no proprietary interests and had full discretion regarding the analysis of data and write-up of the manuscript.

\section{References}

1. [No authors listed]. The effectiveness of intraocular pressure reduction in the treatment of normal-tension glaucoma. Collaborative Normal-Tension Glaucoma Study Group. Am J Ophthalmol. 1998; 126(4):498-505.

2. Heijl A, Leske MC, Bengtsson B, Hyman L, Bengtsson B, Hussein M; Early Manifest Glaucoma Trial Group. Reduction of intraocular pressure and glaucoma progression: results from the Early Manifest Glaucoma Trial. Arch Ophthalmol. 2002;120(10):1268-1279.
3. Kass MA, Heuer DK, Higginbotham EJ, et al. The Ocular Hypertension Treatment Study: a randomized trial determines that topical ocular hypotensive medication delays or prevents the onset of primary openangle glaucoma. Arch Ophthalmol. 2002;120(6):701-713; discussion 829-830.

4. Barkana Y, Anis S, Liebmann J, Tello C, Ritch R. Clinical utility of intraocular pressure monitoring outside of normal office hours in patients with glaucoma. Arch Ophthalmol. 2006;124(6):793-797.

5. Hughes E, Spry P, Diamond J. 24-hour monitoring of intraocular pressure in glaucoma management: a retrospective review. J Glaucoma. 2003;12(3):232-236.

6. Friberg TR, Sanborn G, Weinreb RN. Intraocular and episcleral venous pressure increase during inverted posture. Am J Ophthalmol. 1987;103(4):523-526.

7. Buguet A, Py P, Romanet JP. 24-hour (nyctohemeral) and sleep-related variations of intraocular pressure in healthy white individuals. $A m J$ Ophthalmol. 1994;117(3):342-347.

8. De Vivero C, O'Brien C, Lanigan L, Hitchings R. Diurnal intraocular pressure variation in low-tension glaucoma. Eye (Lond). 1994;8(Pt 5): $521-523$.

9. Rota-Bartelink AM, Pitt A, Story I. Influence of diurnal variation on the intraocular pressure measurement of treated primary open-angle glaucoma during office hours. J Glaucoma. 1996;5(6):410-415.

10. Tajunisah I, Reddy SC, Fathilah J. Diurnal variation of intraocular pressure in suspected glaucoma patients and their outcome. Graefes Arch Clin Exp Ophthalmol. 2007;245(12):1851-1857.

11. Asrani S, Zeimer R, Wilensky J, Gieser D, Vitale S, Lindenmuth K. Large diurnal fluctuations in intraocular pressure are an independent risk factor in patients with glaucoma. J Glaucoma. 2000;9(2):134-142.

12. Collaer N, Zeyen T, Caprioli J. Sequential office pressure measurements in the management of glaucoma. J Glaucoma. 2005;14(3):196-200.

13. Medeiros FA, Weinreb RN, Zangwill LM, et al. Long-term intraocular pressure fluctuations and risk of conversion from ocular hypertension to glaucoma. Ophthalmology. 2008;115(6):934-940.

14. Bengtsson B, Heijl A. Diurnal IOP fluctuation: not an independent risk factor for glaucomatous visual field loss in high-risk ocular hypertension. Graefes Arch Clin Exp Ophthalmol. 2005;243(6):513-518.

15. Leonardi M, Pitchon EM, Bertsch A, Renaud P, Mermoud A. Wireless contact lens sensor for intraocular pressure monitoring: assessment on enucleated pig eyes. Acta Ophthalmol. 2009;87(4):433-437.

16. Lorenz K, Korb C, Herzog N, et al. Tolerability of 24-hour intraocular pressure monitoring of a pressure-sensitive contact lens. J Glaucoma. 2013;22(4):311-316.

17. Mansouri K, Medeiros FA, Tafreshi A, Weinreb RN. Continuous 24-hour monitoring of intraocular pressure patterns with a contact lens sensor: safety, tolerability, and reproducibility in patients with glaucoma. Arch Ophthalmol. 2012;130(12):1534-1539.

18. Mottet B, Aptel F, Romanet JP, Hubanova R, Pépin JL, Chiquet C. 24-hour intraocular pressure rhythm in young healthy subjects evaluated with continuous monitoring using a contact lens sensor. JAMA Ophthalmol. 2013;131(12):1507-1516.

19. Prata TS, De Moraes CG, Kanadani FN, Ritch R, Paranhos A Jr. Posture-induced intraocular pressure changes: considerations regarding body position in glaucoma patients. Surv Ophthalmol. 2010;55(5):445-453.

20. Kiuchi T, Motoyama Y, Oshika T. Influence of ocular hypotensive eyedrops on intraocular pressure fluctuation with postural change in eyes with normal-tension glaucoma. Am J Ophthalmol. 2007;143(4):693-695

21. Sakata R, Aihara M, Murata H, et al. Intraocular pressure change over a habitual 24-hour period after changing posture or drinking water and related factors in normal tension glaucoma. Invest Ophthalmol Vis Sci. 2013;54(8):5313-5320.

22. Renard E, Palombi K, Gronfier C, et al. Twenty-four hour (nyctohemeral) rhythm of intraocular pressure and ocular perfusion pressure in normal-tension glaucoma. Invest Ophthalmol Vis Sci. 2010;51(2):882-889. 
23. Weinreb RN, Liu JH. Nocturnal rhythms of intraocular pressure. Arch Ophthalmol. 2006;124(2):269-270.

24. Bagga H, Liu JH, Weinreb RN. Intraocular pressure measurements throughout the 24 h. Curr Opin Ophthalmol. 2009;20(2):79-83.

25. Liu JH, Weinreb RN. Monitoring intraocular pressure for 24 h. $B r J$ Ophthalmol. 2011;95(5):599-600.

26. Downs JC, Burgoyne CF, Seigfreid WP, Reynaud JF, Strouthidis NG, Sallee V. 24-hour IOP telemetry in the nonhuman primate: implant system performance and initial characterization of IOP at multiple timescales. Invest Ophthalmol Vis Sci. 2011;52(10):7365-7375.
27. Stewart WC, Konstas AG, Nelson LA, Kruft B. Meta-analysis of 24-hour intraocular pressure studies evaluating the efficacy of glaucoma medicines. Ophthalmology. 2008;115(7):1117-1122.e1.

28. Pajic B, Pajic-Eggspuchler B, Haefliger I. Continuous IOP fluctuation recording in normal tension glaucoma patients. Curr Eye Res. 2011;36(12): $1129-1138$

29. Holló G, Kóthy P, Vargha P. Evaluation of continuous 24-hour intraocular pressure monitoring for assessment of prostaglandin-induced pressure reduction in glaucoma. J Glaucoma. 2014;23(1):e6-e12.
Clinical Ophthalmology

\section{Publish your work in this journal}

Clinical Ophthalmology is an international, peer-reviewed journal covering all subspecialties within ophthalmology. Key topics include: Optometry; Visual science; Pharmacology and drug therapy in eye diseases; Basic Sciences; Primary and Secondary eye care; Patient Safety and Quality of Care Improvements. This journal is indexed on

\section{Dovepress}

PubMed Central and CAS, and is the official journal of The Society of Clinical Ophthalmology (SCO). The manuscript management system is completely online and includes a very quick and fair peer-review system, which is all easy to use. Visit http://www.dovepress.com/ testimonials.php to read real quotes from published authors. 